\title{
SANTPEN's SoTL Journey: Building and Using a SoTL Approach Across Institutions
}

\author{
Deborah West $^{1}$ and Helen Stephenson ${ }^{2}$
}

\begin{abstract}
In the current higher education environment, providing high quality teaching and learning experiences to students has moved beyond desirable to essential. Quality improvement takes many forms, but one core aspect to ensure sustainable improvement is the development of a culture of scholarship of teaching and learning (SoTL). Developing such an institutional culture is surprisingly challenging yet essential to improving the status of teaching in higher education (HE), being successful in teaching and learning awards and grants, and, improving the student experience.

The Australian Government's Promoting Excellence Network initiative funds networks to foster collaboration between HE institutions to improve outcomes in national learning and teaching award and grant programs. Supported by this funding, the South Australian / Northern Territory Promoting Excellence Network (SANTPEN), a grouping of six institutions, formed. Bringing together a diverse network of institutions, similar only by virtue of geographic location is challenging.

This paper describes the first three years of SANTPEN's journey from the context of our own development with the concept of SoTL and how we applied this to build a culture of SoTL in and between our institutions. It also demonstrates how a modest budget can be put to effective use to benefit those immediately involved, institutional objectives and the aims of the national funding body. We provide evidence of this effectiveness and conclude with our collective aspirations for the future of SANTPEN and other likeminded and funded networks.
\end{abstract}

Keywords: scholarship of teaching and learning, distributed leadership, community of practice.

\section{Introduction}

The South Australia/Northern Territory Promoting Excellence Network (SANTPEN) was established as one of five national Promoting Excellence Networks in September 2011, under the umbrella of the funding body, the Australian Learning and Teaching Council (ALTC). This program provided a small amount of funding for two years (approximately $\$ 25,000$ per annum) with the aim of developing structures focussed on the recognition and promotion of "good practice in learning and teaching” (Australian Learning and Teaching Council, 2010, p. 4) and "to build and consolidate the capacity of higher education institutions to engage constructively with the programs of the ALTC” (Australian Learning and Teaching Council, 2011, p. 2). This in large part translated to a focus on engagement with the teaching citations, awards, and learning and teaching grants programs. SANTPEN consists of two institutions in the Northern Territory - Batchelor Institute of Indigenous Tertiary Education (BIITE) and Charles Darwin

\footnotetext{
${ }^{1}$ Director, Office of Learning and Teaching, Charles Darwin University, Darwin, Northern Territory, 0909, Australia

${ }^{2}$ Project Manager: Teaching and Learning, Centre for Innovation in Learning and Teaching, Flinders University, Bedford Park, South Australia, 5042, Australia
} 
University (CDU) - and four institutions in South Australia - Flinders University (Flinders), Tabor College Inc. (Tabor), The University of Adelaide (Adelaide), and University of South Australia (UniSA). One nominated person, generally the Institutional Contact Officer (ICO) for the Office for Learning and Teaching $\left(\mathrm{OLT}^{3}\right)$, from each institution administers SANTPEN. Despite this commonality, the SoTL expertise of the project team ranged from 'novice' to 'experienced', with the levels of responsibility and basis of employment being diverse. The mix within the team presented both challenges and opportunities in terms of how individual members and SANTPEN approached their task.

The developmental journey of SANTPEN has played a key role in our progress and in recognising SoTL as a theoretical basis for our work. This journey and SoTL theory have brought to the fore, the need to be able to measure our effectiveness as a network. Yet evidencing the role of what is essentially a community of practice operating across institutional boundaries is difficult. Further complicating this are the institutional and individual efforts that have developed alongside our work but which cannot be directly attributed to SANTPEN. In applying a SoTL approach this struggle has been translated into two key research questions:

1. How can SANTPEN incorporate SoTL into our work?

2. How can SANTPEN most effectively demonstrate the impact of our actions within and across the six partner institutions?

3.

As such, this paper begins by providing background on the concept of SoTL and SANTPEN. It then tells the story of our work to continue the Australian Learning and Teaching Council's (2010, p. 2) priority "to lead and support the transformation of learning and teaching in Australian higher education", in the six SANTPEN institutions using a SoTL informed framework, as a process, and as an outcome. We then present and report against the framework developed to demonstrate the impact of the network.

\section{Scholarship of Teaching and Learning}

There is considerable debate around the term 'Scholarship of Teaching and Learning' (Vardi, 2010). Much of this debate in Australia has been caught up in and driven by political agendas related to how one defines a university, the role of teaching only academics and research rankings (Probert, 2014). The ongoing divide between research and teaching and what is defined as research also contributes to the use of various terms for positioning in the sector and within institutions. For example, up until 2013 the primary funding source for research work in the field of learning and teaching in higher education in Australia was not classified as 'research' funding irrespective of the nature of the project. Rather 'scholarly' approaches and evaluations were encouraged. However, this changed in 2013 with OLT funding being reclassified as category 1 research funding. With that shift, those applying for and receiving grant funding could refer to their work, where appropriate, as research. Due to these and other factors, many writers (Probert, 2014; Sanderson, 2013; Williams, Goulding and Seddon, 2013) in the field return to the work of Boyer to frame and develop a working definition of SoTL.

Rather than debate the definition, it is more useful to highlight the key elements discovery, integration, application and teaching - which help to operationalise the concept as outlined by Boyer (1990). These four elements reflect a systematic approach to the improvement of teaching and learning. This systematic approach can be put in several frames of reference, but very much mirrors a research process. The main difference is the application

\footnotetext{
3 The OLT superseded the ALTC which, in turn, superseded the Carrick Institute for Teaching and Learning.
}

Journal of the Scholarship of Teaching and Learning, Vol. 16, No. 5, October 2016. josotl.indiana.edu 
of this process to teaching and learning as a specific field and the value base which drives it: the improvement of the student learning experience.

In linking this back to the purpose of SANTPEN, drawing on the value base and purpose for the operationalisation is critical. The driving force behind SoTL work spreading beyond small pockets is the idea that it is intended to improve learning and teaching and the student experience. While in the current climate it is essential that this occurs, it does not necessarily mean that it will be taken up by academics as an approach. It has been shown, however, that certain SoTL activities and a coordinated structural approach lead to improved student outcomes. Brew (2012) found that there was a statistical correlation between the teaching of staff who have won teaching and learning awards, and students reporting they had experienced good teaching, appropriate assessment and generic skills development. As such, the use of a SoTL approach is a foundation for improvement in the student experience and also underpins success in learning and teaching citations and awards. While this has always to some extent reinforced our thinking, such a focus has evolved over time as we have continued on our developmental journey.

\section{SANTPEN's Developmental Journey}

\section{Background}

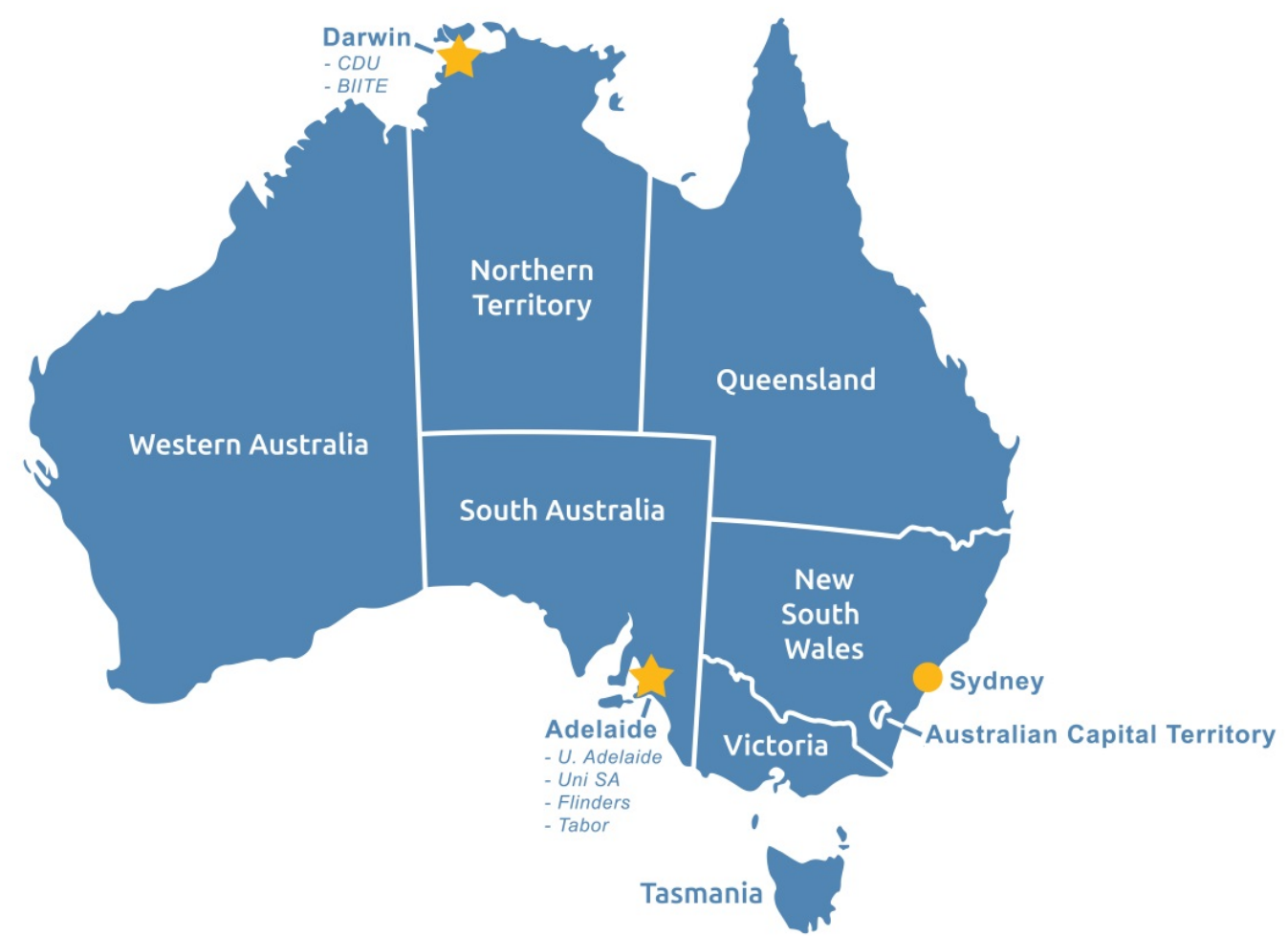

Figure 1. Map of Australia identifying locations of SANTPEN institutions.

As noted above, SANTPEN is comprised of six institutions spread across South Australia (SA) and the Northern Territory (NT) of Australia. Each institution, and in fact location, has its own challenges and provides the broader context for our development. South Australia and the Northern Territory represent the central corridor of the continent. The capital cities of each are separated by over $3,000 \mathrm{~km}$ and the population of each is small in comparison to other Australian states. Besides differences in geographical terrain, the operating context of each SANTPEN institution is varied. These were pivotal considerations during the development of SANTPEN's aims and deliverables.

Journal of the Scholarship of Teaching and Learning, Vol. 16, No. 5, October 2016. josotl.indiana.edu 
South Australia (SA) has three publicly funded higher education institutions within $15 \mathrm{~km}$ of each other, two international universities, and eight other higher education providers. Like our NT counterparts, the three publicly funded institutions in SA have multiple city and regional campuses and in some cases (e.g. Flinders University), interstate campuses as well. In such an environment, competition for student enrolments is lively and each institution strives to differentiate itself from the other, particularly in terms of student experience and research investment.

By contrast, the NT has only two publicly funded institutions: CDU and BIITE. Both have multiple campuses across the Territory, and CDU has several locations interstate. CDU has a strong focus on flexible modes of study with students being drawn from around the country. As the name would suggest, BIITE has a clear focus in serving Indigenous students. So while CDU also has a strategic focus on Indigenous education, the two institutions are in a less directly competitive environment.

Irrespective of geographical location, groups formed in the 1990s and early 2000s of likeminded Australian institutions are one method by which institutions differentiate themselves. Flinders and CDU are both members of the Innovative Research Universities (IRU), Adelaide aligns with the Group of Eight (Go8), and UniSA with the Australian Technologies Network (ATN). Each group has distinguishing features identifying its member universities. BIITE and Tabor Adelaide, a smaller and privately established higher education provider with a Christian perspective, are not in any of these groups.

In addition to each public institution's membership in different groups, a number of higher education national networks and collaborations exist and have state branches operating in South Australia. However, none of these networks or groups had a commitment to, or engagement with, NT higher education providers, and none had a similar remit to SANTPEN. This is an important consideration, as CDU and BIITE are quite isolated in a variety of ways and what SANTPEN was able to offer was a strong and formalised connection around SoTL.

\section{Establishing SANTPEN - the first year}

The contextual differences between institutions and lack of previous collaboration amongst project team members were pivotal considerations during the development of SANTPEN's aims and activities. While these differences appeared challenging at first, in actuality, they ensured a relatively level playing field. For example, SANTPEN provided members with an incentive and a forum in which to discover more about one another. It brought together a breadth of knowledge and experience to draw upon, and opened up opportunities to engage with experts within other national PEN networks.

As an ALTC/OLT funded network, SANTPEN's aims specifically utilised an appreciative perspective, in that the aims "focus on recognition, values, and affirmation" of the participating institutions and the funding body (Whitney \& Trosten-Bloom, 2010, p. 12). SANTPEN's aims identified the importance of developing relationships conducive to funding intentions, as well as members' various institutional priorities and needs. Developed in 2011 and outlined below, SANTPEN's aims remain unchanged today. A key feature of SANTPEN's success was the communication between project team members, their commitment and involvement in identifying these aims, and the way in which they are enacted.

1. To develop a collegial network valuing the diversity and inclusiveness of the South Australian and Northern Territory higher education institutions.

2. Support the advancement of teaching and learning priorities at each member institution acknowledging the diversity that exists and the opportunities collaboration provides. 
3. Provide and maximise on opportunities to share resources, disseminate good practice and innovations for the sustainable, long-term enhancement of learning and teaching.

4. To build a broad cultural base for Scholarship of Teaching and Learning (SoTL) across the six SANTEPN institutions ${ }^{4}$

During the start-up time each SANTPEN institution agreed to design and lead a fullday teaching and learning event at their institution, which focused on a particular OLT program (e.g. awards or grants). Funding was equally distributed to SANTPEN institutions to cover costs associated with the event, including guest speakers, catering and a meeting of the project team. Interstate project team members received additional finance to cover flights and accommodation, ensuring that they could attend events held interstate. In SANTPEN's first two years all project team members attended each event and in many cases facilitated a session at each event. In 2012, three SANTPEN events were held, two in South Australia and one in the Northern Territory. Themes included OLT Teaching Awards, OLT Learning and Teaching Grants, and the Scholarship of Teaching and Learning.

As part of SANTPEN's commitment to "provide and maximise opportunities to share resources, disseminate good practice and innovations for the sustainable, long-term enhancement of learning” a SANTPEN website was created (see http://santpen.weebly.com/). The website, hosted independently of member institutions, provides a public face for SANTPEN and enables the promotion of events and resources originating from events to be shared publicly.

\section{SANTPEN - the second year}

Over the next twelve months SANTPEN continued to deliver on its stated aims. Distributing responsibilities for particular event activities amongst SANTPEN team members, while ensuring that institutional specific information, such as varying administrative protocols, were on hand for participants, created further opportunities to share information. In doing so, team members learnt how specific elements of an OLT program were administered at each institution. As a result we were able to take this new knowledge back to our own institutions and implement or adapt teaching and learning award and grant institutional processes. As exemplified by the following email communication, "SANTPEN has provided a platform for institutional change, including increased funding for awards and grants, implementation of Teaching and Learning Committees” (Personal Communication, Manager Learning and Engagement, October 2012).

SANTPEN provided team members with a range of professional development opportunities, including in the area of leadership, which Bryman (2007, p. 696) defines "in terms of influencing and/or motivating others towards the accomplishment of ...goals”. At a basic level team members were able to focus on one component of an OLT program, developing and expanding expertise with the support of fellow team members. In some cases team members with less experience or confidence were paired with a more experienced team member to facilitate sessions. This mentoring approach further developed relationships and expertise.

Through a distributed leadership approach, SANTPEN enabled a more robust sharing of information, regular opportunities to hear from people at other institutions involved with OLT applications, a day dedicated to a specific OLT program and greater 'pulling' power to recruit guest speakers and facilitators. As well as increasing SANTPEN's effectiveness, distributed leadership not only respected SANTPEN's aims, but also the knowledge and

\footnotetext{
${ }^{4}$ Source: http://santpen.weebly.com/
}

Journal of the Scholarship of Teaching and Learning, Vol. 16, No. 5, October 2016. josotl.indiana.edu 
expertise of individual project team members and the needs of their institutions. The SANTPEN team was demonstrating leadership as "an outcome of cooperation between individuals that manifest(ed) itself in their shared direction, the alignment of behaviour, and their mutual commitment to a particular practice” (Von Krogh, Nonaka, \& Rechsteiner, 2011, p. 253).

A difficulty of networks such as SANTPEN is their ability to evidence, other than anecdotally, the transference of its efforts to increased awareness and evidence of SoTL advancements within the relatively short time frame provided in a two-year funding period. While we were confident that SANTPEN's activities and the collegial network was contributing to increased awareness of SoTL and its application to teaching and learning awards and grants nominations, differentiating SANTPEN's efforts from institutional initiatives was problematic and somewhat counterproductive to the rationale of SANTPEN's objectives to support institutional teaching and learning priorities.

This is also connected to the area of academic leadership and the influence of various team members within their own institution and the structure of the institution itself. As noted by Southwell, Scoufis and West (2008, p. 7) "the term leadership is open to a plethora of interpretations and is relative and context specific.” However, institutional leadership around learning and teaching rests at various levels (Southwell et. al, 2008) and is therefore distributed at least to some extent in all institutions. A key challenge for the team based on its diversity, both in terms of team membership and institutional context was to maximise our opportunities for influence, harness our leadership capability within our realm of influence and be able to identify its impact.

Throughout this time the project teams' own awareness and interpretation of SoTL and the level of recognition and application within member institutions increased. Evidence of a sound knowledge and application of SoTL underpins all teaching and learning proposals and nominations regardless of its level - institutional or national. Discussions of our own experiences assisting staff members with teaching and learning award and grant applications identified an increasing need to develop underpinning skills and awareness around SoTL as a stepping stone for future development. SANTPEN made a decision to run activities to address this gap in experience and understanding of SoTL.

\section{Redefining SANTPEN's position and focus}

In mid-2013, the OLT called for applications from PENs for further funding to "consolidate... (the work of the PENs) into 2014 and 2015" and SANTPEN discussed how best to promote SoTL within our institutions while modelling a SoTL approach ourselves. ${ }^{5}$ This was quite a critical turning point, but also a controversial one as it brought to light the issue of product versus process.

For some SANTPEN members who are professional staff, the idea of promoting and 'doing' SoTL sat outside their job specification, to work with applicants, to develop and submit awards and grant applications. The expectation was that applicants required assistance to frame their submission within guidelines but largely came to the table with existing knowledge of SoTL and evidence (in the case of awards). Additionally in that context the professional role did not require research activity or outputs. Other members, particularly academic staff, had roles which were much broader and the idea of developing SoTL capacity as the underpinning knowledge and skill set was seen as the foundation for future success.

The other factor that appeared to contribute to these different perspectives was the institutional context in terms of the size of the institution, staff experience and turnover and

\footnotetext{
${ }^{5}$ This paper being one artefact of our own SoTL discussion and efforts.
} 
underlying capacity in SoTL. For smaller institutions or those with a higher turnover rate, there were simply fewer academics with sufficient experience to be able to apply for awards or grants and therefore the focus was on building a future pool of applicants. Additionally, the institutional view on SoTL as a means to improve student experiences was critical as it provided the driver to embed the approach more broadly.

Even if one accepts that SoTL is the foundation for teaching awards and grants, the idea of how this should be operationalised can be quite different from one institution to another. For some in SANTPEN, the focus is on changing the institutional culture to improve learning and teaching, while for others it is not. The idea of SANTPEN members modelling SoTL was seen by some members as being important. That is, in addition to discussing and delivering workshops about SoTL, SANTPEN should model it. The idea of 'walking the talk' was seen as having multiple benefits including:

- $\quad$ evidencing and evaluating our approach.

- $\quad$ improving our program through evidence and reflection.

- $\quad$ being able to use our modelling as an example in workshops.

- $\quad$ increasing our skills and credibility.

- $\quad$ providing evidence for future SANTPEN funding applications.

\section{Developing our understanding of SOTL}

Working through this operationalisation required unpacking the various ways that SoTL is referred to and creating a working definition and a framework for moving forward. Within the literature, SoTL is seen as both a product (where a piece of work is produced) and a process for undertaking the work (Trigwell, 2012; Dawson, 2012). These two elements also link to the idea of SoTL as a 'framework' which, while, implied needs to be articulated and applied.

For the purpose of this paper, we consider SoTL to be an approach that should underpin good teaching and learning but also be recognised as a process. A useful way to consider SoTL as an approach is how the University of South Australia promotes SoTL (Sanderson, 2013):

- Being a reflective teacher - gathering data about their teaching activity, and analyse and reflect on it in a critical manner so as to improve their own practice.

- Being a scholarly teacher - engaging with discussion and debates about teaching in the literature contributed by scholars in their own disciplines and using this to shape their practice.

- Contributing to the scholarship of teaching - presenting their own analysis of teaching, using relevant data they have related to the work of others, and which has been critiqued and validated by their peers so as to contribute more widely to a better understanding of teaching and learning.

We have incorporated these elements into our own practice:

1. We reflect on our own workshops, consider how we have run these sessions and look at ways to improve them.

2. Our approach and the material that we present are based on theory and literature. We provide resources from a range of authors/thinkers on SoTL and have robust discussions about SoTL as a team and within workshops with participants.

3. While we have shared our knowledge and contributed to thinking about SoTL within our sessions and for some more broadly within our institutions, dissemination beyond our network is increasingly seen as important.

Journal of the Scholarship of Teaching and Learning, Vol. 16, No. 5, October 2016. 
In summary, the application of SoTL is now central to our work and our understanding of SoTL continues to grow. A further challenge is to translate this into a SoTL framework for SANTPEN and to apply a SoTL process to gather evidence.

\section{Building our SoTL framework}

The key to our future work rests in building a framework and evidence base to identify our impact on developing a SoTL culture within and between institutions. As noted previously, for some of the SANTPEN group this is critical, for others it is not due to their role. Our flexibility in enabling this to happen is based on our earlier agreement around SANTPEN which included:

- $\quad$ participating in research into our own practice where an individual's role allows this.

- $\quad$ being able to contextualise to our own location when we run a workshop.

- following up in our institutions as appropriate and build on the sessions.

- running joint sessions so that staff from different institutions can attend.

- $\quad$ sharing resources with other PENs and colleagues via our website.

This means that not all institutions will participate in data collection in alignment with this goal. Additionally, given that institutions vary considerably we might expect that the evidence would vary, as would the impact. However, the following is the set of data that is being developed:

\section{Table 1. Data Framework}

\begin{tabular}{|c|c|c|}
\hline \multirow[b]{2}{*}{$\begin{array}{l}\text { Type of Data } \\
\text { Demographics on } \\
\text { number of events } \\
\text { and attendance }\end{array}$} & Purpose & Method \\
\hline & $\begin{array}{l}\text { Assess the scope and reach of } \\
\text { participation } \\
\text { Explore questions related to } \\
\text { discipline }\end{array}$ & $\begin{array}{l}\text { - Registration records } \\
\text { - Cross reference to } \\
\text { applications for } \\
\text { awards/grants }\end{array}$ \\
\hline $\begin{array}{l}\text { Feedback on } \\
\text { sessions, including: } \\
\text { - usefulness of the } \\
\text { material covered } \\
\text { - delivery of } \\
\text { workshop } \\
\text { - points for further } \\
\text { clarification }\end{array}$ & $\begin{array}{l}\text { Improve our own practice } \\
\text { Improve the usefulness of the } \\
\text { sessions } \\
\text { Test efficacy of content and } \\
\text { approach }\end{array}$ & $\begin{array}{l}\text { - Survey of participants } \\
\text { to provide feedback on } \\
\text { the session content and } \\
\text { delivery } \\
\text { - Pre and post survey of } \\
\text { participants to gauge } \\
\text { understanding of SoTL }\end{array}$ \\
\hline $\begin{array}{l}\text { SANTPEN group } \\
\text { reflections }\end{array}$ & $\begin{array}{l}\text { Identify areas for improvement of } \\
\text { our own practice } \\
\text { Identify process issues }\end{array}$ & $\begin{array}{l}\text { - Qualitative data } \\
\text { captured via team } \\
\text { debriefing }\end{array}$ \\
\hline $\begin{array}{l}\text { Applications/success } \\
\text { rates for } \\
\text { institutional }\end{array}$ & $\begin{array}{l}\text { Identify the impact of the } \\
\text { SANTPEN events on applications } \\
\text { for awards and grants. }\end{array}$ & $\begin{array}{l}\text { - Number of applications } \\
\text { for internal awards and } \\
\text { grants }\end{array}$ \\
\hline
\end{tabular}

Journal of the Scholarship of Teaching and Learning, Vol. 16, No. 5, October 2016. josotl.indiana.edu 


\section{teaching and \\ learning awards and grants}

- Number of successful applications

- Number of applications that subsequently progress to national applications

Applications/success
rates for external
teaching and
learning awards
and grants

Identify the impact of the SANTPEN events on applications for awards and grants.
- Number of applications for external awards and grants

- Number of successful applications

\section{Collaboration Identify how the network has between institutions changed collaboration}

- Number of grants with collaboration between the institutions (and participants within and across sessions)

- Additional activities occurring between institutions

- Sharing of practice

\begin{tabular}{lll}
\hline Participant led & Identify where participants & $\bullet$ Contact with \\
initiatives & subsequently lead an initiative & SANTPEN member \\
& & with details of \\
& event/initiative
\end{tabular}

\begin{tabular}{lll}
\hline $\begin{array}{l}\text { Institutional } \\
\text { changes }\end{array}$ & $\begin{array}{l}\text { Identify if/where SANTPEN has } \\
\text { had some influence on institutional }\end{array}$ & $\begin{array}{c}\bullet \text { Documentation of } \\
\text { changes }\end{array}$
\end{tabular}
processes, policy or strategy

It is necessary to note that due to the developmental process that has taken place the full data set is not available from the beginning of the project.

\section{Findings}

Demographics

Journal of the Scholarship of Teaching and Learning, Vol. 16, No. 5, October 2016. 
In the first round of funding SANPTEN held six events: two in Darwin (NT) and four in Adelaide (SA). These included a variety of guest speakers and workshop activities related to the development of award and grant applications.

A total of 228 registrations were received for these events, representing 204 people, the majority of whom were early career academics. While full data is not available for all participants, cross referencing registration details with publicly available professional details (when available) enabled us to determine some participants' broad classification of position titles (Table 2) and broad fields of education (Table 2a). Broad fields of education have been identified in accordance with the Australian Standard Classification of Education (Australian Bureau of Statistics, 2015a).

\section{Table 2. SANTPEN participant demographics}

\begin{tabular}{ll}
\hline Broad classification of participant position titles & Number of participants \\
\hline Lecturer & 34 \\
Senior lecturer & 14 \\
Research & 11 \\
Head or Deputy Head of School or Division & 11 \\
Other & 117 \\
\hline
\end{tabular}

Table 2a. Participants' broad fields of education

\begin{tabular}{ll}
\hline Broad field of education & Number of participants \\
\hline Education & 66 \\
Health & 47 \\
Society and culture & 21 \\
Management and commerce & 13 \\
Mixed fields programmes & 8 \\
Natural and physical sciences & 6 \\
Architecture and building & 3 \\
Creative arts & 3 \\
Engineering and related technologies & 3 \\
Participants in other broad fields & 58 \\
\hline
\end{tabular}

The second round of funding had a very different focus, with participation in SANTPEN events in 2014 by invitation only (with the exception of one open event in 2015). The events in this round had a far greater emphasis on SoTL as an underpinning framework for the development of awards and grants and in developing networks. A total of 62 people attended events held in SANTPEN's second funding phase. Of these 62 people, 15 had attended events held in the first funding phase.

\section{Participant feedback}

At the conclusion of SANTPEN events participants were asked to complete an evaluation form. Initial surveys did not have ethics clearance as they were deemed to be evaluative and there was no intention of using the data for any purpose other than improvement of the workshops. As a result these data are unable to be included in this paper. However, with the evolution of the network, ethics approval was sought and granted in May 2014 to survey all past and future participants of the workshops. A survey consisting of seven multiple choice questions and five 
open-ended questions was distributed in May 2014 to all participants from all SANTPEN activities run to that point. Due to the time lag between participants attending events and the survey, the response rate was low.

Of the survey responses received, participants indicated that they found the SANTPEN activities were useful in providing information on writing and applying for awards and grants, the focus of the workshops in SANTPEN's first two-years. Institutional success rates in this area is explored later in this paper.

When asked how participants' involvement in SANTPEN activities had prompted them to reflect on their teaching practice. Survey responses included:

This is an ongoing process, and as part of my job I always think about these things, but events like SANTPEN events help you to focus and to develop networks of support to act on your thoughts.

(Senior Lecturer, continuing position, 10-19 years full-time equivalent experience).

Really reinforced importance of reflection and on ensuring assessment aligns with learning outcomes and taht (sic) I deliver sessions appropriate to these.

(Lecturer, continuing position, 6-9 years full-time equivalent experience).

While people remained interested in SANTPEN holding writing workshops for grants and awards, there was a growing number of requests for activities with a focus on developing scholarly approaches to learning and teaching, and writing about learning and teaching for publication. The increased interest in SoTL was timely given that SANTPEN had already applied for, and been successful, for a further 18 months of funding to deliver three, two day SoTL workshops.

While there has undoubtedly been an increased focus on scholarly learning and teaching approaches within academic positions over the past few years, responses like those above demonstrate the diversity of SANTPEN's participant expertise. Importantly though, the responses indicate that dedicated time with colleagues is valued, people appreciate the topics being discussed, and are thinking about their own practice.

Through discussion, people are able to compare their learning and teaching approaches, and sources of evidence with those being undertaken elsewhere. Discussing learning and teaching with colleagues is an important step towards bridging reflective teaching with scholarly teaching. Discussion provides an opportunity for people to develop networks and better understand the varying contexts and needs of institutions and disciplines. People are able to develop connections and, importantly, begin to recognise where common needs and wants exist, including as one lecturer (continuing position, 6-9 years full-time equivalent experience) highlighted, "how my activity fits within University and national priorities."

\section{SANTPEN group reflections}

The SANTPEN project team has built in a range of activities that specifically incorporate reflection. This occurs from the planning stage of an event (where we reflect on previous events and priorities), to peer review of our own sessions and post event debriefing and reflection. This has been facilitated through face-to-face meetings, which have been particularly important in developing relationships amongst team members, regular teleconferences, and less formal occasions, for example over dinner. While the more formal aspects are all minuted providing a mechanism for review and ongoing reflection, the team dinners have provided team members with the opportunity to learn more about each other's institution and working environment. 
Within our reflections we look at:

- $\quad$ how we can improve our own practice in running the workshops;

- themes that emerge from participants around the 'muddiest' SoTL points or what participants would like more information about;

- how we can improve our own institutional practice; and

- $\quad$ how we can improve our evidence of impact.

Such reflections have contributed to a process of continual improvement in our practice and our network approach.

In terms of content of the sessions, reflection on actual applications and the 'muddiest points' led some of the team to recognise that a number of academic staff who were keen to apply for a teaching and learning grant had very little knowledge and understanding of the current national priorities. Applicants were also often unaware of priorities and activities within their own institution. Greater awareness of national and institutional priorities is essential for successful grant funding. Additionally, ethical considerations and clearances remained for many an area of confusion. To this end SANTPEN held an event including an expert panel specifically focussed on researching learning and teaching in higher education to explore the priorities and identify gaps. The issue of ethics has also been given more attention in the workshops.

Institutional practices for the administration of teaching and learning awards and grants were discussed and resulted in changed practices at some institutions. This has resulted in the implementation of institutional learning and teaching awards and grants and, at some institutions, increased success with national awards and grants. Smaller institutions have received support from larger institutions with peer review of nomination materials.

It is through this reflection that we have clarified our own approach and the need to have greater clarity and emphasis on the fact that SoTL is the underpinning framework for awards and grants as well as the improvement of learning and teaching. It has also led us to refine our own data collection processes and evidence our work. Evidencing our work has led to the development of the framework presented in this paper.

\section{Application success rates}

In 2014 SANTPEN tracked the success rate of participants for both internal (institutional) and external (nationally funded) awards and grants. A review of awarded national grants and awards indicates an increase at SANTPEN institutions in 2012 and 2013. However, with the exception of Flinders University, this trend did not continue in 2014. It is difficult to ascertain the reasons for this. Several more obvious possibilities exist including a decrease in the total funding available for awards and grants, a decrease in the number of awards and grants awarded, and changes to the application requirements and submission dates for external grant schemes. Additionally, a change in SANTPEN's focus from institutional events to state or territory based scholarship of teaching and learning days may also be a contributing factor.

More specifically, the following table shows the number of participants who have been successful in citations, awards and grants either internally or externally since participating in the program.

Table 2. Success of SANTPEN participants in citations, awards and grants $(\mathrm{N}=\mathbf{2 0 5})$

\begin{tabular}{ll}
\hline Internal Award & 3 \\
\hline
\end{tabular}

Journal of the Scholarship of Teaching and Learning, Vol. 16, No. 5, October 2016. josotl.indiana.edu 


\begin{tabular}{lc}
\hline Internal Grant & 2 \\
\hline External Citation & 11 \\
\hline External Award & 0 \\
\hline External Grant & 8 \\
\hline
\end{tabular}

\section{Collaborations between institutions}

It should be remembered that while South Australian SANTPEN institutions are located within a small geographical area, significant competitive pressures previously hindered collaboration. Further, collaboration between SA and NT institutions was almost non-existent with the exception of Flinders University, who offer several joint programs with CDU.

Since SANTPEN's inception there is greater collaboration, at least at the levels of the staff involved, between institutions on numerous points. In SA there are increased opportunities for staff to network, as learning and teaching events held by one institution are now sometimes opened to staff from other institutions. One institution is now delivering a graduate certificate course at another institution and there are occasions when SANTPEN team members are able to connect people with similar interest, academic needs and expertise between institutions. This has resulted in two of the SANTPEN team members (CDU \& BIITE) collaborating on an unrelated national grant application, which was successful. An additional project which involves Flinders and CDU participants both within and outside of the SANTPEN leadership group has been funded by the IRU.

Increasing collaboration between member institutions is an important aspect as noted by one SANPTEN participant:

The development of networks between universities is very important, especially when it comes to national grants, so keep up the good work, and perhaps think about ways to expand SANTPEN even further.

(Senior Lecturer, continuing position, 10-19 years full-time equivalent experience).

\section{Participant led initiatives}

A key challenge of a network such as SANTPEN is to increase the distributed leadership and have those who attend events take a leading role in operationalising the impact. While there has been some anecdotal evidence of participants sharing their experiences with other colleagues, the nature of this is difficult to establish. However, one of our CDU sessions has led to a participant setting up a research network around investigating evidence based education. This network as a spin-off of the SANTPEN session includes participants who have been to SANTPEN sessions from both CDU and BIITE.

\section{Institutional changes}

The ability of SANTPEN team members to influence institutional processes, policies and strategies varies according to the position and level of influence that the team member has locally. It is fair to say that processes related to awards and grants have been reviewed and modified at least to some extent in all SANTPEN institutions. The impact on institutional policies and strategies is less so and much more difficult to link to the activities of SANTPEN. However, several examples do exist.

As a result of discussion through SANTPEN, Flinders University implemented new administrative processes for the submission of national teaching and learning awards, fellowships and grants in late 2013. These administrative processes demonstrate a concerted

Journal of the Scholarship of Teaching and Learning, Vol. 16, No. 5, October 2016. josotl.indiana.edu 
effort to build capacity through a distributed leadership approach within Flinders University by:

- building awareness of national teaching and learning awards, grant and fellowship requirements and assessment processes;

- promoting peer feedback that supports people in their development of these applications; and

- $\quad$ encouraging faculty and school staff with specific responsibilities to support grant applications to attend SANTPEN and OLT events.

At CDU some of the activities and work of the network can be seen to have influenced the institutional policies and strategies to some extent. More broadly, the events have gained some prominence, further highlighting how SoTL underpins awards and grants. Additionally, discussion around the concept and framework for increasing SoTL has been present in various policy and procedural reviews including the student evaluation of learning and teaching survey and changes to the ethics approval process related to teaching and learning activities.

BIITE's involvement in SANTPEN led to the implementation of teaching and learning awards at that institution in 2013. On a national level there is far greater awareness of BIITE and increased requests for their involvement in national grants.

\section{Discussion}

As the SANTPEN network has developed over time, a clearer focus on SoTL as the underpinning framework has evolved. This has resulted in the network unpacking and focusing on various SoTL elements. Initially, we focussed on the products of SoTL in the form of awards and grants. While we always considered SoTL to some extent as being the process by which these products would be achieved, it took time for us to be clearer about this. Articulating and applying a SoTL framework to our own work has been a more recent dimension. However, we now have a clearer way of gathering data which will support our claims that the network has an impact on the product as well as the process.

We have become more explicit about how leadership and communities of practice can help to support SoTL, including within SANTPEN itself, as well as in broader institutional communities. Data collection relating to these elements is now more strategic and purposeful and is beginning to demonstrate this impact. The application of leadership and communities of practice are mechanisms applied to the development of SoTL and sit within a suite of concepts which contribute to improvements.

There are several limitations to this study which flow from the fact that we did not employ systematic data collection processes to our work until quite recently. While retrospective collection of data goes some way to addressing this, it remains problematic as we cannot clearly demonstrate the longer term impact at present. This is compounded by the complexity of the improvement of learning and teaching and its connection to SoTL, which makes it difficult to directly attribute any improvements or changes to our work specifically. However, with the framework now in place we can identify the elements that we see as related to our program and track their progress. This information will allow us to leverage our own institutions and outside bodies to gain further funding to continue the journey.

\section{Conclusion}

SANTPEN is now in its fourth year of funding and operation. The project team has formed a strong bond around a common interest of SoTL as it relates to the promotion and development of teaching awards, and teaching and learning grants at institutional and national levels. Within

Journal of the Scholarship of Teaching and Learning, Vol. 16, No. 5, October 2016. josotl.indiana.edu 
the team institutional competiveness and uniqueness are acknowledged fondly and with occasional humour. A community of leaders has formed to support each other and increase our understanding and expertise in SoTL.

Our deepening understanding of SoTL as both a product and process and how this might apply to our program delivery as well as our own development as a network has been a key part of our journey. Tackling SANTPEN's aims from a SoTL approach has enabled us to develop a framework to collect a range of evidence demonstrating our impact within complex and multifaceted environments. As a network we have been able to reach more people, provide access to interstate and international guest speakers, and importantly reintroduce a collegial atmosphere into an increasingly competitive and potentially isolating experience.

SANTPEN team members are positive about the future and remain proactive and committed to the advancement of SoTL within our institutions. The SoTL framework is an overall approach contributing to SANTPEN's continued effectiveness within the Australian higher education sector.

\section{Acknowledgements}

We wish to acknowledge the support and advice of our SANTPEN colleagues, Dr Jurg Bronnimann, Batchelor Institute of Indigenous and Tertiary Education, Dr Gavin Sanderson, University of South Australia, Dr Stephen Spence, Tabor Adelaide and Dr Ashleigh Ward, University of Adelaide, in the writing and submission of this paper.

Support for SANTPEN has been provided by the Australian Government Office for Learning and Teaching. The views in this paper do not necessarily reflect the views of the Australian Government Office for Learning and Teaching.

\section{References}

Australian Bureau of Statistics (2015a). Australian standard classification of education.Canberra, Australia: ABS. Retrieved from: http://www.abs.gov.au/AUSSTATS/abs@.nsf/Latestproducts/02D465407348EBEACA256A AF001FCA57?opendocument

Australian Bureau of Statistics (2015b). Data by Region. Canberra, Australia: ABS. Retrieved from: http://stat.abs.gov.au/itt/r.jsp?databyregion

Australian Learning and Teaching Council (2011). Request for Expression of Interest: StateBased Promoting Excellence Networks. Strawberry Hills, Australia: ALTC.

Australian Learning and Teaching Council (2010). Transforming learning and teaching in Australian higher education: ALTC strategic plan 2010 - 2013. Strawberry Hills, Australia: ALTC.

Boyer, E. (1990). Scholarship reconsidered: Priorities of the professoriate. Lawrenceville, NJ: The Carnegie Foundation for the Advancement of Teaching.

Brew, A. (2012). Developing the Scholarship of Teaching and Learning at an Institutional Level. Unpublished conference presentation at the International Scholarship of Teaching and Learning Conference, 24-27 October, Hamilton, Canada.

Bryman, A. (2007). Effective Leadership in Higher Education: A Literature Review. Studies

Journal of the Scholarship of Teaching and Learning, Vol. 16, No. 5, October 2016. josotl.indiana.edu 
West and Stephenson

in Higher Education, 32(6), 693-710.

Dawson, P. (2012). Principles and Practices of Effective Teaching [Video Podcast].

Retrieved from:

https://www.youtube.com/playlist?list=PLTSnkUkjDJGWcFgwru4_Mpje6-z9iZUny

Sanderson, G. (2013). Innovating and Transforming University Teaching Through the Scholarship of Teaching and Learning. Proceedings of the TARC International Conference on Learning and Teaching: Innovation and Transformation in Higher Education Conference Proceedings, Kuala Lumpur, Malaysia, 21-22 October 2013, Tunku Abdul Rahman University College.

Southwell, D., Scoufis, M. \& West, D. (2008). 'Caught between a rock and several hard places': Cultivating the roles of the Associate Dean (Teaching and Learning) and the Course Coordinator. Strawberry Hills, Australia: Carrick Institute.

Trigwell, K. (2012). Scholarship of teaching and learning. In L. Hunt \& D. Chalmers (Eds) University Teaching in Focus: A learning-centred approach (pp. 253-267). London: ACER Press and Routledge, Taylor \& Francis Group.

Vardi, I. (2010). The changing relationship between the Scholarship of Teaching (and Learning) and universities. Higher Education Research and Development, 30(1), 1-7.

Von Krogh, G., Nonaka, I., \& Rechsteiner, L. (2011). Leadership in organizational knowledge creation: A review and framework. Journal of Management Studies, 49(1), 240-277. doi: 10.1111/j.1467-6486.2010.00978.x

Wenger, E., McDermott, R. A., \& Snyder, W. (2002). Cultivating communities of practice: A guide to managing knowledge: Boston, MA: Harvard Business Press.

Whitney, D., \& Trosten-Bloom, A. (2010). The power of appreciative inquiry: A practical guide to positive change. San Francisco, CA: Berrett-Koehler Publishers. 